\title{
Non-Humean Laws and Scientific Practice
}

\author{
Robert Smithson
}

(Forthcoming in Erkenntnis, please cite published version)

\begin{abstract}
Laws of nature have various roles in scientific practice. It is widely agreed that an adequate theory of lawhood ought to align with the roles that scientists assign to the laws. But philosophers disagree over whether Humean laws or non-Humean laws are better at filling these roles. In this paper, I provide a new argument for settling this dispute. I consider (epistemically) possible situations in which scientists receive conclusive evidence that - according to the non-Humean - falsifies their beliefs about the laws, but which - according to the Humean - does not falsify their beliefs about the laws. I argue that, in these possible scenarios, all law-related aspects of scientific practice would remain unchanged. In other words, scientists would treat the regularities "preferred" by the Humean as the laws of nature. On this basis, I conclude that non-Humean laws fail to align with scientific practice.
\end{abstract}

\section{Introduction}

Laws of nature have various roles in scientific practice. It is widely agreed that an adequate theory of lawhood ought to align with the roles that scientists assign to the laws. But philosophers disagree over whether Humean laws or non-Humean laws are better at filling these roles.

It would be straightforward to resolve this question if Humeans and non-Humeans disagreed on which specific regularities count as laws of nature. Then, we could simply consider which regularities scientists treat as laws to settle the issue. But of course, Humeans and non-Humeans agree that (e.g.) Schrödinger's Equation is a law; they disagree over what makes it so. 
But while Humeans and non-Humeans agree on which regularities actually count as laws, there are (epistemically) possible scenarios in which they disagree on which regularities count as laws. Now, imagine that scientists were to discover that such a scenario obtained. This would provide a "test case" for deciding the debate over Humeanism. By seeing which regularities scientists treat as laws in these cases-those predicted by the Humean vs. those predicted by the non-Humean - we would have clear evidence regarding whether Humean laws or non-Humean laws better align with scientific practice.

In this paper, I develop a version of this strategy to challenge non-Humeanism. The argument appeals to certain (epistemically) possible "Humean Döppelgangers" of the actual world: worlds that agree with the actual world on the Humean base, but which (according to the non-Humean) have different laws. Humeans and non-Humeans disagree on which regularities count as laws in these Döppelgangers; Humeans will say that the laws are what we ordinarily take them to be, while non-Humeans will say that the laws are different.

My argument considers (epistemically) possible situations in which scientists receive conclusive evidence that such a Döppelganger scenario obtains. In other words, they receive evidence that - according to the non-Humean - falsifies their judgments about the laws, but which - according to the Humean - does not falsify their judgments about the laws. I argue that, in these possible scenarios, all law-related aspects of scientific practice would remain unchanged. In other words, scientists would treat the regularities "preferred" by the Humean as the laws. On this basis, I conclude that non-Humean laws fail to align with scientific practice.

\section{Background}

After some brief background in this section, I present the argument against the non-Humean in sections 3-4. In section 5, I conclude the paper by sketching how the 
argument can also be used to deflect some common objections to Humeanism.

\subsection{Laws in scientific practice}

I will begin by reviewing the roles of laws in scientific contexts. Here, we can view scientific contexts as contexts where (i) our ultimate evidence is from observations and empirical measurements and (ii) reasoning involves inductive, abductive, and statistical inferences from that evidence (Roberts $(2008,264)$ ).

(1) Fixed points in counterfactual reasoning: Lange (2000, ch. 2) and Roberts (2008, chs. 5-7) observe that laws are held fixed in scientific counterfactual reasoning in ways that mere regularities are not. More precisely, Lange and Roberts defend the principle of Nomological Preservation $(\mathrm{NP})^{1}$ :

NP: $\forall Q \forall P$ (if $Q$ is consistent with the lawhood of all and only the actual laws of nature, and the lawhood of all and only the actual laws of nature logically entails $P$, then: if $Q$ had been the case, then $P$ would still have been the case)

Roberts $(2008,273-291)$ argues that, in order to recognize something as an observation or measurement, one must assume the truth of the counterfactual conditionals described by NP. This is because we cannot distinguish conditions under which a measurement procedure is reliable without holding laws fixed in counterfactual reasoning.

(2) Supporting induction: Laws also have a special role in scientific inductive reasoning. Says Lange $(2000,21)$ : "we can regard the observed instance as confirming the hypothesis "inductively" ... only if we believe that the hypothesis may state a law." Lange offers this example: because it would be a mere coincidence that all coins received as change today are pennies, we do not regard receiving a penny as change as evidence that the next received coin will be a penny. By contrast, because we think that it follows (or may follow) from the laws, the hypothesis that all samples of a compound boil

\footnotetext{
${ }^{1}$ This formulation is from Roberts $(2008,191)$. Lange $(2000,53)$ calls his formulation $\Lambda$-preservation.

${ }^{2}$ Lange $(2000,143-156)$ adjusts this characterization to avoid counterexamples, but I will set these details aside.
} 
at temperature $C$ is thought to be inductively confirmed by an observation of a given sample of that compound boiling at $C$.

(3) Laws and explanation: Scientists use laws to explain the facts subsumed under them. For example, suppose an electron curves in a magnetic field. Scientists explain this trajectory by appealing to the Lorentz force law, which states that a particle of charge $q$ with a velocity $v$ in an electric field $E$ and a magnetic field $B$ experiences a force of $F=q E+q v \times B$. By contrast, the mere coincidence that all coins received as change today were pennies does not explain the fact that the third coin thus received was a penny. ${ }^{3}$

(4) Foundation of important scientific distinctions: Scientists appeal to laws, but not other regularities, in order to determine what is possible. Maudlin $(2007,7-8)$ offers this example: because a closed universe and an open universe are both consistent with Einstein's gravitational law, physicists believe that both types of universe are possible.

Roberts $(2012,12 \mathrm{ff})$ provides a second example: we use statistical thermodynamics to explain why a glass of ice water will contain no solid ice after sitting outside on a hot day for five minutes. The explanation is, roughly, that the set of possible initial states of the water molecules that would lead to solid ice after five minutes is vanishingly small within the space of all possible initial states. But to make sense of notions like "vanishingly small" in this context, we need to justify a choice of measure over the states of the system. This measure, in turn, requires the distinction between the dynamically possible vs. merely logically possible trajectories of a system of particles through phase

\footnotetext{
${ }^{3}$ It is sometimes claimed that, in addition to explaining their instances, laws explain regularities as a whole. This is plausible for accidental regularities and for regularities corresponding to non-fundamental laws. For example, Kepler's laws can be derived from (and explained by) Newton's laws plus assumptions about initial conditions (see, e.g., Fowler (2002)). Both Humeans and non-Humeans accept that laws explain these kinds of regularities.

As for the regularities corresponding to the fundamental laws themselves: this is less obvious. While non-Humeans share this intuition, it is not clear that scientists use the laws this way. For example, when reading a physics textbook, one does not typically read anything about what explains the regularity corresponding to Schrödinger's Equation. So for simplicity, I will follow the recent literature by focusing on the role of laws in explaining their instances. This will not affect the discussion ahead. (And at any rate, Dorst (2019, fn. 3) and Hicks (ms) argue that Humeans laws are capable of explaining (fundamental) regularities as a whole. So this is unlikely to be a deciding factor in the dispute over Humeanism.)
} 
space.

(5) Objects of scientific discovery: Finally, laws are objects of scientific discovery. Scientists do not merely investigate particular facts; from these particular facts, they seek to infer claims about general laws. ${ }^{4}$

\subsection{Humean Supervenience}

What must the laws be like if they are to fill the roles required of them by scientists? One central disagreement is over whether Humean laws or non-Humean laws are better able to perform these various types of scientific work. Humeans and non-Humeans disagree over the following thesis ${ }^{5}$ :

Humean Supervenience about Laws (HS): no two possible worlds differ on what is a law of nature unless they also differ on their Humean bases.

Intuitively, the Humean base will include particular facts about the existence of physical objects, their (non-dispositional) physical properties, and their spatiotemporal relations to one another. It will exclude facts that involve laws of nature, causation, counterfactuals, or dispositions. This intuitive characterization of the Humean base will suffice for the discussion ahead.

One corollary of the denial of HS is the claim that the actual world has Humean Döppelgangers: worlds that share the actual world's Humean base but which have different laws. ${ }^{6}$ For example, Armstrong (1983, 71-72) argues that any true universal regularity (among instances of universals) entailed by the Humean base in the actual world could either be a law or fail to be a law. Similarly, Lange $(2000,51)$ says:

\footnotetext{
${ }^{4}$ See Lange (2000, 2.4) for discussion.

${ }^{5}$ See, e.g., Carroll $(1994,58)$ and Loewer (1996).

${ }^{6}$ Strictly speaking, the denial of HS does not entail that there are actual-world Döppelgangers. One might say, for example, that some possible worlds share a Humean base while having different laws, even though the actual world is not among them. But see Earman \& Roberts $(2005,263)$ for discussionof why this stance would be implausible.
} 
That two possible worlds could have exactly the same non-nomic facts, but differ in which non-nomic facts state laws, should not really be surprising, considering that the laws in a given world are tied up not just with what in fact comes to pass there, but also with what would have happened there had certain circumstances unrealized in that world instead come to pass there.

\subsection{The formalized argument}

As mentioned in the introduction, these (alleged) Döppelgangers of the actual world can serve as "test cases": cases that help decide whether Humean laws or non-Humean laws better align with scientific practice. Here is the intuitive idea. Let's suppose that scientists were to receive (near-enough) conclusive evidence that-according to the nonHumean - showed that we actually live in such a Döppelganger. In other words, suppose that scientists were to receive conclusive evidence that - according to the non-Humeanreveals their judgments about the laws (though not their judgments about the Humean base) to be false. ${ }^{7}$

If scientists track non-Humean laws, then receiving this evidence should have a dramatic effect on scientific practice. Scientists would be learning that they were completely wong about the laws, and so we would expect this discovery to affect many areas of scientific practice. But I will argue that this non-Humean "prediction" is not borne out. This, in turn, is evidence that scientific practice does not, in fact, track non-Humean laws. Here is the formal argument:

\section{Argument:}

Let $E$ be (near-enough) conclusive evidence that-according to the nonHumean - reveals scientists' judgments about the laws (though not their judgments about the Humean base) to be false.

Premise 1: If scientists were to receive $E$, this would not alter those aspects of scientific practice relating to the laws.

\footnotetext{
${ }^{7}$ As I will discuss in 3.2, the descriptions of the evidence in last two sentences are not quite equivalent. I will use the latter description when speaking precisely, but the former is useful for intuitive purposes.
} 
Premise 2: If scientists would not alter those aspects of scientific practice relating to laws upon receiving $E$, then non-Humean laws do not fill the roles that laws have in scientific practice.

Conclusion: non-Humean laws do not fill the roles that laws have in scientific practice.

I will defend the argument's two premises in the next two sections.

\section{Defending premise 1}

In this section, I will consider two thought experiments in which scientists receive evidence $E$ that-according to the non-Humean-reveals their judgments about the laws (though not their judgments about the Humean base) to be false. I will argue that receiving such evidence would not alter the "law-related" aspects of scientific practice.

\subsection{Preliminaries}

Here are some preliminary notes:

(a) The Oracle: To simplify discussion, I will suppose that $E$ is (near-enough) conclusive evidence. To illustrate this, I will suppose that (in each case) scientists receive $E$ as testimony from an all-knowing, completely trustworthy Oracle.

Of course, the appeal to an Oracle is fanciful, but it does no essential work in the argument ahead. Ultimately, it does not matter how scientists end up accepting $E$. If one prefers, one can instead suppose that scientists accept $E$ because they hear some persuasive philosophical argument for $E$.

(b) Scientific contexts: We can distinguish scientists' reactions to the Oracle's testimony immediately after receiving it from their responses upon returning to scientific work. I will now explain why only the latter responses are relevant to this paper.

My argument focuses on how laws are used in scientific practice. For this reason, we need to consider how laws are used in the typical contexts of scientific work: con- 
texts where scientists are engaged in inductive reasoning from evidence obtained through observation and measurement. But the context immediately following the Oracle's testimony is not a typical scientific context. For this reason, scientists' immediate response to the Oracle is less relevant than how this testimony ultimately influences their work.

Focusing on "long term" responses also helps avoid some obvious complications with immediate reactions. To assess the latter would require a poll. And we have no reason to expect that scientists would respond to such a poll in any uniform way. After all, the norms governing how scientists use laws in their everyday work may not hold in the immediate aftermath of the Oracle's testimony. But for long-term reactions, no polls are needed. This is because we know a lot about the roles of laws in scientific practice (see 2.1). By reflecting on these roles, we can make confident predictions about how scientists would respond upon returning to scientific work (I will discuss this point in greater detail in 3.4.)

One might worry that long-term reactions encounter their own difficulties: scientists may simply have forgotten, stopped caring, or changed their mind about the Oracle's testimony. In fact, I agree that these factors may affect scientists' long-term reactions. But as I discuss in 3.4, these possibilities actually support my ultimate interpretation of the cases. Another worry with long-term reactions is that scientific practice may change in light of the Oracle's testimony. I discuss this possibility in 4.2.

(c) Theological descriptions: Few scientists are familiar with the terminology philosophers use when discussing HS. But if scientists do not understand the Oracle's testimony, their responses will tell us little about scientific practice. To finesse this issue, I will invoke the conceit of a divine lawgiver. We can imagine God performing two tasks when creating the world. First, God assigns initial conditions to the particles. Second, God issues a set of decrees (e.g., "Let it be the case that $f=m a . ")$ that the particles therefore must obey throughout history. Of course, most non-Humeans do not actually appeal to a divine lawmaker. But non-Humeans should allow that, in an (epistemically) possible 
world where there is a God issuing decrees, the laws supervene on those decrees.

Most people have an intuitive grip on the idea of a divine lawmaker. Indeed, this is why non-Humeans sometimes appeal to this idea when intuitively motivating the "governing" conception of laws. ${ }^{8}$ So by appealing to a divine lawgiver, we can set aside worries about whether scientists understand the Oracle.

\subsection{Case 1: The Humean world}

Suppose that scientists visit the all-knowing, perfectly-trustworthy Oracle. There, they hear the following speech:

"At the fundamental level, there is a vast mosaic of particular matters of fact, and that is all. But there is nothing over and above the mosaic that governs these particular matters of fact. For example, it is not as if God issued a command that particles follow in any given pattern."

According to the non-Humean, the above testimony establishes that we live in a world with no laws. So if scientists are tracking non-Humean laws, we should expect this revelation to have a dramatic effect on scientific practice. But would it? To assess this question, I will consider the various specific roles that laws have within scientific practice (see 2.1).

(N.b.: As I stipulate the example, the Humean world is a Döppelganger in the sense described in 2.2. But note that the Oracle says nothing specific about what the mosaic is like; she only says that nothing governs it. Insofar as this testimony leaves open what might happen in the future, it technically does not establish that we live in a Döppelganger. But it does provide conclusive evidence that-according to the non-Humean - reveals scientists' law judgments (though not their judgments about the Humean base) to be false. This is all that is required for my formal argument (see 2.3). This point only becomes relevant when discussing the inductive role of laws - see (iii)

\footnotetext{
${ }^{8}$ See Carroll (1994, 17-18) and Lange (2000, 51). See also Beebee (2000, 580-581) and Loewer (1996, 115) for discussion from a Humean perspective.
} 
below.)

(i) Counterfactual reasoning: According to the non-Humean, the Oracle's testimony implies that there are no (interesting) true counterfactuals (for there are no laws to support to them). So if scientists track non-Humean laws, we should expect them to stop relying on counterfactual reasoning upon receiving the Oracle's testimony. Perhaps we can imagine certain scientists doing exactly this in the moments immediately following the testimony. They might say things like "There is no fact of the matter about how this particle would curve if we increased this magnetic field" or "Who knows what would happen to these binary stars if the mass of one of them increased by half?"

But, upon reflection, it is difficult to believe that any scientist could or would persist in this attitude upon returning to actual scientific work. For example, imagine students in a physics lab asking questions like "But what would happen if we increased the magnetic field?" and "What would happen if we coupled the pendula together?" And to each question, the TA replies: "Who can say?" (or else: "We cannot make sense of that question."). Or imagine students writing "There is no fact of the matter" every time their homework asked about what would happen if the projectile was fired at a different angle or if the spring was stretched twice as far. This would be useless.

Similarly, Roberts $(2008,273-291)$ argues that it would be impossible for scientists to distinguish the conditions under which a measurement procedure is reliable without holding laws fixed in counterfactual reasoning. So without counterfactual reasoning, scientists would have no grounds for relying on measurements.

The broader point is that many scientific projects would be undermined without counterfactual reasoning. But scientists would not stop pursuing these projects (in the successful way that they did before) simply because they learned that the world lacked non-Humean structure. (For now, I hope the reader finds this last claim intuitive. But I will return to this point in 3.4, where I will provide specific reasons for thinking that scientists would continue pursuing these projects using counterfactual reasoning). 
One might worry that this begs the question against the non-Humean, who says that there are no (interesting) true counterfactuals in the case described. But at present, I make no claims about which counterfactuals (if any) are actually true. I only claim that post-Oracle scientists would continue reasoning counterfactually so that they could continue pursuing their projects in the effective way they did before.

There is probably an even more basic reason why scientists would continue reasoning counterfactually: it is almost certainly psychologically impossible for normal adult human subjects to fail to engage in counterfactual reasoning. There is a large psychological literature on the prevalence of counterfactual reasoning and its importance to deliberation and behavior regulation. ${ }^{9}$ I will return to this point in 3.4.

(ii) Laws and explanation: According to the non-Humean, the Oracle's testimony implies that particular physical facts cannot be explained using laws (for there are no laws). So, then, we should expect scientists to stop giving informative explanations of particular physical facts. And, perhaps, this is what certain scientists would do immediately after the testimony. They might say "There is no explanation of why the electron curved when we increased the magnetic field."

But again, there is no chance that scientists would persist in this attitude once returned to everyday work. Imagine, for example, a physics lab where the students are asking questions like "Why did the electron curve so much more that time?" and "Why did the electron curve up instead of down that time?" And imagine the TA responds, in each case: "There is no explanation for this." This would be pedagogically useless; it would be very difficult (if not impossible) to teach physics by providing the same uninformative answer any time someone asks for an explanation. ${ }^{10}$

The non-Humean might suggest that post-Oracle scientists would adjust their ap${ }^{9}$ See, e.g., Stalnaker (1996), Gilovich, et al (2003), Epstude \& Rose (2008), Summerville \& Roese
$(2008)$.
${ }^{10}$ The non-Humean might say that, even if it is pedagogically useless, telling the students that there
are no explanations is useful for another reason: it conveys an important fact about the world revealed
to the Oracle. (I thank an anonymous referee for this suggestion.) I address this objection below in fn.
12. 
proach to teaching by replacing explanatory questions with something else. But I submit that scientists would not radically alter their pedagogy simply because of the Oracle's testimony. (For now, I hope this claim seems intuitive, but I provide four arguments for it in 3.4 and 3.5.)

All of this may seem to beg the question against the non-Humean, who says that physical facts have no explanation in the described possibility. But, again, I only claim that scientists would, as a matter of fact, continue offering the same kinds of explanations they did before.

Just as before, we might appeal to facts about human psychology as well. It is a part of our psychological makeup to make explanatory inferences. Could scientists permanently "choose" to believe that there is no explanation for why the electron happened to curve the way it did? I will return to this point in 3.4.

(iii) Inductive reasoning: As discussed in 2.1, scientists require the distinction between laws and merely accidentally true regularities in order to distinguish legitimate inductive inferences from illegitimate ones (recall the example comparing the case of boiling points to the case of coins received as change). According to the non-Humean, the Oracle's testimony implies that scientists can no longer draw this distinction. So if scientists are tracking non-Humean laws, the Oracle's testimony should undermine the inductive practices of scientists.

But this would certainly never happen. Making predictions is an invaluable scientific project, and scientists would not stop pursuing this project simply because they learned that the world lacked non-Humean structure. In addition, it is almost certain that we are psychologically incapable of foregoing our inductive practices in the way that would be required (in this case) if scientists tracked non-Humean laws. For example, suppose we hold fixed our total evidence about the past. It is doubtful that we are psychologically capable of failing to draw any distinction between regularities that are confirmed by their instances and those that are not. 
(iv) Important scientific distinctions: As discussed in 2.1, thermodynamics requires a distinction between the dynamically possible vs. logically possible trajectories of a system through phase space. If the non-Humean is correct, then the Oracle's testimony implies that there is no such meaningful distinction. So if post-Oracle scientists tracked non-Humean laws, they could no longer use thermodynamics to give explanations or make predictions. But scientists would not stop studying thermodynamics just because of what they learned from the Oracle. I clarify exactly why this is difficult to imagine in $3.4 .^{11}$

(v) Objects of scientific discovery: Perhaps, after the Oracle's testimony, we can imagine certain scientists succumbing to defeatist attitudes: "Why bother using the particle accelerator? After all, there are no laws to discover anyway." But, again, this attitude would not persist. The search for lawful regularities is itself a foundational scientific project, and scientists would not stop pursuing this project simply because they learned that the world lacked non-Humean structure.

\subsection{Case 2: The fragile world}

Here is a second case. In this example, let $D_{0}, D_{r_{1}}, \ldots$ be the total momentary physical states of our universe at times $t=0, t=r_{1}, \ldots$, and let $\left\{D_{0}, D_{r_{1}}, \ldots\right\}$ be the total set of such states across all times $t$. The Oracle declares:

"At the beginning of time, God assigned the universe initial state $D_{0}$. Since that time, the universe has always conformed to Newton's equations. But this is not because God decreed that $F=m a$, that $F_{G}=\frac{G m_{1} m_{2}}{d_{1,2}^{2}}$, etc. Instead, it is because God issued the following conditional decree:

-if the universe is in one of the states from the set $\left\{D_{0}, D_{r_{1}}, D_{r_{2}}, \ldots\right\}$,

\footnotetext{
${ }^{11}$ On the other hand, Humeans seem to accept a different range of nomically possible worlds than do non-Humeans. So, if scientists were to learn that the world was Humean, wouldn't this require changes in how scientists treat nomic possibility? I consider this objection in 3.6.
} 
then: $f=m a, F_{G}=\frac{G m_{1} m_{2}}{d_{1,2}^{2}}, \ldots$

-else: all matter annihilates.”

According to the non-Humean, the above testimony establishes that we are in a Döppelganger. Rather than there being no laws at all (as in 3.2), this is a case where the laws are different from what we suppose; specifically: the laws take the conditional form described by the Oracle.

How would this testimony affect law-related aspects of scientific practice? For some of these roles, the non-Humean predicts no difference. For example, the non-Humean will not expect this testimony to affect inductive reasoning. But for two of the roles, the non-Humean predicts dramatic differences.

(i) Counterfactual reasoning: The non-Humean will say that this is a world where, if the universe were to enter any state other than one of its actual states, all matter would annihilate. And perhaps, immediately after the Oracle's testimony, we can imagine certain scientists exclaiming: "So if the weight had been released, it would not have fallen. Instead, all matter would have annihilated!"

But even these scientists would soon return to reasoning counterfactually as they had before. To see why, this time imagine a physics TA replying "The world would annihilate" in response to every question about what would happen if the magnetic field were adjusted. Or imagine a student writing "The world would annihilate" any time their homework asked them what would happen if the magnetic field had been stronger. This would be ridiculous. (Just as in 3.2, I make no claims (at present) about which counterfactuals are true. I only make a claim about scientists' long-term reactions to the Oracle's testimony.)

Why exactly would this be ridiculous, if in fact the world is fragile in this way? In response: it would be next to impossible to teach physics if students received the same, trivial answer anytime they asked their TA this sort of question during their lab section. And imagine how little understanding a student would get from a homework set 
if they wrote the same, trivial answer every time they were asked what would happen were conditions different. (Indeed, almost any standard physics homework problem would become completely intractable. Instead of using the traditional equations to calculate what would happen under certain described conditions, students would have to do exhaustive empirical investigations to figure out whether the conditions described in the problem ever have or ever will obtain. Of course, this would be impossible, and no student could ever learn physics this way.)

The absurdity of using the divine decrees to evaluate counterfactuals would arise in any context where scientists engage in counterfactual reasoning. To modify an example from Dorst (forthcoming), suppose a physicist is called as an expert witness in a case involving a car wreck. Imagine that, when asked what would have happened if the driver had braked earlier, the physicist responds: "The world would have annihilated." When asked what would have happened if the roads were dry (or if the tires were different, or ...), imagine the physicist always giving the same response.

These examples show how evaluating every counterfactual in the same, trivial way each time would be as useless as not reasoning counterfactually at all. But without (non-trivial) counterfactual reasoning, many important scientific projects (such as taking measurements, teaching science, and even giving expert testimony) would suffer. And scientists would never let the Oracle's testimony impede these important scientific projects. They would not, for example, dramatically revise the homework sets assigned to their students. (I leave this point intuitive for now, but will defend it at length in 3.4.)

Again, one might worry that this begs the question against the non-Humean, who says that, in the fragile world in question, all counterfactuals ought to be evaluated in the same, trivial way. But at present, I make no claims about which counterfactuals (if any) are actually true. I only claim that scientists would continuing pursuing their projects (including the teaching of science) after the Oracle's testimony, which would 
require them to reason counterfactually as they did before.

(ii) Important scientific distinctions: The non-Humean will say that, given the Oracle's testimony, the only dynamically possible trajectory of a system is its actual trajectory. But then there can be no interesting measure defined over the states of the system's phase space, and so there can be no thermodynamical explanations. So if scientists track non-Humean laws, they would have to stop relying on thermodynamics when giving explanations and making predictions. But I suggest that this would never happen. I clarify the reasons why below.

\subsection{How can we know how scientists would respond?}

Once one has seen the basic form of the thought experiments, it is easy to generate additional examples. These cases support premise 1 (see 2.3):

Premise 1: If scientists were to receive $E$, this would not alter those aspects of scientific practice relating to laws of nature.

But the non-Humean might reply: how can I be so confident that scientific practice would go on as before? Maybe it would, but then again maybe it wouldn't. Isn't this just a sociological question? To address this concern, I will now distinguish three independent arguments for thinking that scientific practice would not change.

(I) Indifference: The most basic reason why the Oracle's testimony would not alter scientific practice is the fact that, throughout the course of their everyday work, scientists are completely indifferent to the debate over Humeanism. For example, when in the lab, scientists never pause to consider the possibility that we might be in some Döppelganger scenario (or how we might rule out such a possibility). They do not, for example, go around wondering whether Schrödinger's Equation really is a law of nature (unless, of course, there is concern that Schrödinger's Equation fails to truly describe the Humean base). 
In 3.1, I considered the possibility that scientists' long-term reactions are explained by their forgetting or ceasing to care about the Oracle's testimony. In fact, I agree that these factors may affect scientist's long term reactions. But the reason we can easily imagine scientists forgetting or ceasing to care about the Oracle is because scientists are typically indifferent (in the course of their everyday work) to what might or might not exist over and above the mosaic.

Suppose it is true that, in their everyday work, scientists are indifferent to what might be "behind the scenes" of the Humean mosaic. Then it is implausible to think that scientists would alter scientific practice upon receiving the Oracle's testimony. To alter their scientific practice, scientists would have to deeply care about the metaphysical underpinnings of the laws. But in reality, thoughts about what is "behind the mosaic" rarely, if ever, cross their mind. ${ }^{12}$

(II) Psychological necessity: Next, I turn to a consideration alluded to throughout 3.2: that it would psychologically impossible for scientists to alter their practice in the way that would be necessary if they tracked non-Humean laws. For example, I have suggested that it is psychologically impossible for adult humans to (permanently) forego reasoning counterfactually at all (as in the Humean world) or to (permanently) rely on world-annhilation counterfactuals (as in the fragile world).

To be clear, I am not denying that we can, at any given moment, evaluate counterfactuals in the way that the non-Humean thinks is appropriate. Instead, I am claiming that it would be psychologically impossible, in these cases, to go about the business of our everyday lives while continuing to reason counterfactually "in the non-Humean way." This is no speculative psychological hypothesis: simply try to plan the rest of

\footnotetext{
${ }^{12}$ The present discussion also helps address the objection from fn. 10: that post-Oracle scientists would start saying "There are no explanations" because (according to the non-Humean) this is an important metaphysical fact about the world. While philosophers are interested in whether there is something "behind the scenes" governing the trajectories of electrons, this kind of fact is not important to scientists in their everyday work. After all, scientists rarely (if ever) think about the debate over Humeanism. (If the reader is not convinced, I note that both (II) and (III) also tell against the suggestion that post-Oracle scientists would stop giving informative explanations.)
} 
your day, or write a philosophy paper, without relying on counterfactual reasoning. ${ }^{13}$ This point applies to all adult humans and so to scientists in particular. Even if they tried (in these cases) to reason counterfactually in the way that the non-Humean thinks appropriate, they would not be able to do so - at least not for very long.

This kind of argument may not apply to every one of the roles considered in 3.2 and 3.3. But I think that something similar applies with inductive reasoning (in the Humean world): I doubt that we are psychologically capable of failing to draw any distinction between regularities that are confirmed by their instances and those that are not (assuming our total evidence about the past is held fixed). The same goes for explanatory reasoning as well: we are not psychologically capable of going about our everyday lives while continuing to view everything as lacking an explanation.

(III) Continuing the successful pursuit of scientific projects: I have presented cases where, according to the non-Humean, either the laws do not exist ( $c f$. the Humean world) or the laws are "useless" for the roles they are supposed to have in scientific practice ( $c f$. the fragile world). Throughout 3.2-3.3, I argued that various scientific projects would (at the very least) be adversely affected were scientists tracking non-Humean laws in these cases.

Here were some of the examples: if scientists evaluated counterfactuals in the "nonHumean way" it would harm projects such as teaching physics, taking measurements, and giving expert testimony. The teaching project would also suffer if (as the non-Humean predicts) scientists in the Humean world stopped asking explanatory questions. Without distinguishing inductively-supported generalizations from those not so supported (in the Humean world), the project of making predictions would be impossible. Failing to distinguish dynamically from logically possible trajectories through phase space would undermine the study of thermodynamics. This merely scratches the surface: without anything suitable to fill roles (i)-(v), many other projects - e.g., manipulating nature,

\footnotetext{
${ }^{13}$ And, at any rate, there is extensive empirical support for the prevalence of counterfactual reasoning and its importance to deliberation, planning, and behavior regulation - see, e.g., fn. 9.
} 
designing new technologies, unifying physical phenomena, etc.-would suffer (and may not even be possible at all). ${ }^{14}$

The non-Humean may say that, as disappointing as all of that would be, post-Oracle scientists would just have to temper their expectations and ambitions. ${ }^{15}$ But even the non-Humean must acknowledge that, in the specific scenarios in question, scientists could pursue their projects just as successfully as they did before. This is because both scenarios are Döppelgangers ${ }^{16}$ of the actual world throughout their entire history. So, for example, these scenarios agree with the actual world on every observable matter of fact. ${ }^{17}$ From this we know that scientists in these scenarios manifestly have been successful at making predictions, teaching physics, manipulating nature, etc.; indeed, they have been exactly as successful as scientists in the actual world. And because these scenarios are Döppelgangers of the actual world throughout their entire history, we also know that post-Oracle scientists would continue to be just as successful at making predictions, manipulating nature, and so on (were they to attempt to do so).

(Insofar as they deny that Humean laws are robustly explanatory, non-Humeans will deny this point when it comes to projects involving explanation. As I discuss in 3.6, Humeans will disagree. But at present, we can set aside the question of whether Humean laws are as robustly explanatory as primitive laws are supposed to be. This is because it is clear that there are, at the very least, certain specific explanatory projects that would remain viable after the Oracle. For example, Bhogal (forthcoming) discusses how scientists use laws to unify physical phenomena. Even the non-Humean must acknowledge that, because the test cases are Döppelgangers, post-Oracle scientists could pursue

\footnotetext{
${ }^{14} \mathrm{I}$ discuss the unification case shortly hereafter.

${ }^{15}$ I thank an anonymous referee for raising this objection.

${ }^{16}$ One caveat: since these scenarios contain Oracle testimony, they do not share quite the same Humean base as the actual world (which does not contain such testimony). But this technicality can be set aside. What is important for the current argument is that, throughout their entire history, these scenarios are exactly like the actual world in terms of which "lawlike regularities" (e.g., $f=m a, F_{G}=\frac{G m_{1} m_{2}}{d_{1,2}^{2}}$ ) obtain.

${ }^{17}$ With one irrelevant exception-see previous footnote.
} 
this project just as successfully as before. Since post-Oracle scientists would be able to continue successfully pursuing projects such as this, they would do so. But this would require scientists to continue using laws in explanations. ${ }^{18}$ )

In summary: each of the roles (i)-(v) is important for some central scientific project(s) or other. So if scientists stopped using laws in a certain role, the corresponding project(s) would (at the very least) be adversely affected. But in fact, these projects could be accomplished just as successfully in the test cases as in the actual world (since the test cases are perfect Döppelgangers). So, given the value of these projects, scientists would continue pursuing them (in the optimal way). And so they would continue using laws in each of the roles (i)-(v).

\subsection{Objection 1: altering scientific practice?}

I have argued that scientists would not let the Oracle's testimony impede their valuable projects. But might the testimony still alter scientific practice such that scientists would pursue these projects differently? For example, I earlier discussed how the explanatory role of laws is important to projects like teaching physics (see 3.2). But perhaps scientists could successfully accomplish this and other projects by "replacing" their explanatory questions with something else. ${ }^{19}$

It is worth emphasizing that both the indifference argument and the psychological necessity argument (see (I) and (II) from 3.4) directly tell against the proposal that scientists would alter their practice in this way. However, the present suggestion would undermine argument (III). So I will now provide two responses.

(IIIa) The unavailability of "replacement" practices. Let's suppose that post-Oracle TAs in the Humean world no longer ask (or give informative answers to) explanatory

\footnotetext{
${ }^{18}$ The non-Humean may reply that, even so, post-Oracle scientists could not accomplish the project of giving "governing explanations": the kinds of explanations that primitive laws are supposed to provide (see 3.1). But it is doubtful that this is a genuine scientific project, given that scientists are typically indifferent to the debate over Humeanism. See Bhogal (forthcoming) for further discussion of the distinction between metaphysical explanations and the nomothetic explanations given by scientists.

${ }^{19} \mathrm{I}$ thank an anonymous referee for this objection.
} 
questions like "Why did the electron curve?" If they are to still help their students, what might they ask instead? We might imagine them asking about prediction: "Why should we have expected the electron to curve?" The problem with this suggestion is that - according to the non-Humean - the Oracle's testimony also undermines scientists' inductive practices (see role (iii) of 3.2). So predictive questions are not available to the non-Humean scientist as a replacement; insofar as post-Oracle scientists ask such questions, this is direct evidence against the non-Humean.

Of course, one can also imagine the TA asking counterfactual questions (e.g., "What would the electron do if the field was increased?") or questions about what is nomically possible (e.g., "Would it be possible for the electron to curve along such-and-such trajectory?"). But according to the non-Humean, these other law-related aspects of scientific practice are also undermined by the Oracle (see 3.2 ). So these options are not available to replace explanatory questions either.

Could there be other nearby questions available to the TA? This is difficult to imagine because, with roles (i)-(v) in 3.2, I already addressed all of (what are typically regarded to be) the important roles of laws in scientific practice. If there is some other useful nearby question, it would have to involve some new role for lawlike regularities (which is not itself undermined by the Oracle). But if there was such a role, we might wonder why scientists were not already using laws in this capacity. At any rate, it would be the burden of the objector to defend such a proposal. ${ }^{20}$

(IIIb): The unsuitability of replacement practices. Let's set aside the above response and suppose that the Oracle's testimony is-by the non-Humean's lights - compatible with scientists' inductive practices. I will argue that, even so, inductive questions would not be a suitable replacement for explanatory questions.

Let's grant, for the sake of argument, that TAs could still successfully teach physics

\footnotetext{
${ }^{20} \mathrm{As}$ an alternative, one might imagine scientists questions such as "Under the fiction that there are laws, what explains ...?" or "Under our changed understanding of laws, what explains ....?" In effect, these questions would allow (non-Humean) scientists to maintain their explanatory practices post-Oracle. I think these proposals are best understood as an objection to premise 2, so I address them in section 4 .
} 
even after replacing explanatory questions with inductive ones. Even so, there are other scientific projects that could not be successfully pursued with this (or any other) replacement, such as the project of providing unifying explanations. As discussed in 3.4, post-Oracle scientists would be able to continue successfully pursuing this project (and therefore would do so). But this, in turn, shows that scientists could not merely replace the explanatory role of laws with something else.

More generally: perhaps there are some projects that could be accomplished just as well without using laws in their explanatory capacity. But there are others that could not. So scientific practice could not be altered in this way without loss. But there is no need for such loss, given that the test cases are Döppelgangers. So to avoid such loss, scientists would continue giving informative explanations using laws.

The situation is even worse for the non-Humean when we consider the other roles of laws. For example, suppose scientists stop making predictions. What could they possibly do instead that would allow them to accomplish their projects as successfully as before? They might say "Electrons have done X in this situation every time in the past," but this is hardly an appropriate surrogate. Similarly, what could scientists possibly use as a replacement for counterfactual reasoning? No one has ever found a way "replace" counterfactual reasoning with reasoning that does not rely on counterfactuals.

\subsection{Objection 2: other aspects of scientific practice?}

While I have provided several arguments for why scientific practice would not change after the Oracle's testimony, one might worry that there is contrary evidence as well. For example, Humeans and non-Humeans seem to disagree on which situations are nomically possible (e.g., a world with all the same laws as our own but with only one particle moving uniformly through space). They also seem to disagree about how to evaluate nested counterfactuals (e.g., "had there been nothing but a lone electron, then had there been more electrons than one, the force between any two electrons would have 
accorded with Coulomb's law" ${ }^{21}$ ). They also seem to disagree on whether laws explain their instances (for how could Humean laws explain particular facts if-according to the Humean - the mosaic of particular facts explains the laws?). Insofar as scientists talk about these issues, their practice seems to align with the non-Humean. So this seems to provide evidence that scientists are tracking non-Humean laws, which in turn is evidence that scientific practice would change after the Oracle's testimony. ${ }^{22}$

In response: I think it is a constraint of adequacy on any theory of lawhood that it align with scientific practice, including how scientists talk about nested counterfactuals, nomic possibility, and so on. And it is true that many traditional Humean accounts have failed this constraint. But recent, more sophisticated versions of Humeanism are designed to avoid these problems. For example, Roberts $(2008$, chs. 3, 10) provides a contextualist treatment of law statements that the Humean can use to account for how scientists approach nested counterfactuals and nomic possibility. ${ }^{23}$ Similarly, Loew \& Jaag (forthcoming) provide their own proposal for how the Humean can account for nested counterfactuals. Loewer (2012), Hicks \& van Elswyk (2015), Dorst (2019), and Hicks (2020) have argued that Humeans laws can (without circularity) explain their instances.

Of course, the non-Humean may disagree that these recent Humean proposals are adequate. $^{24}$ And, regardless, the above proposals are concerned with certain specific aspects of scientific practice; even if they were all successful, this would not establish that Humeans can agree with non-Humeans on every aspect of scientific practice.

But establishing this claim is not required for my argument, for two reasons. The first reason concerns the argument's place in the overall dialectic. Suppose we grant that Humeans have not, as of yet, shown that Humean laws fully align with scientific

\footnotetext{
${ }^{21}$ See Lange $(2009,54)$ for this example.

${ }^{22}$ I thank an anonymous referee for this objection.

${ }^{23} \mathrm{I}$ discuss this account below in section 5 .

${ }^{24}$ For example, see Lange's (2013) response to one recent attempt to show that Humean laws can explain their instances.
} 
practice. Even so, I suspect that many Humeans recognize that this is a burden they must discharge (hence all of the recent Humean efforts to account for this or that aspect of scientific practice). And, of course, such Humeans expect that they can ultimately establish this result. Non-Humeans disagree. But still, we have a kind of stalemate: at the very least, both Humeans and non-Humeans expect that their account will ultimately align with scientific practice. One can think of my argument as an attempt to break this stalemate. By moving to the epistemic possibilities described by the Oracle, we move to cases where it is agreed on all sides that Humean and non-Humean accounts diverge in concrete ways. And this is why the Oracle's pronouncements serve as good "test cases" (see section 1).

But there is a second, more fundamental point: even if we grant that the Humean has trouble with (e.g.) nested counterfactuals, the fact remains that the non-Humean must still address the arguments for Premise 1. In 3.2-3.5, I provided several concrete, independent arguments for why scientific practice would not change in situations where the non-Humean predicts that it would change. These arguments did not appeal to any premises about what existing Humean accounts can or cannot explain; indeed, these arguments did not mention the Humean at all (aside from the claim that scientists are indifferent to the debate over Humeanism). ${ }^{25}$ So the arguments of 3.2-3.5 remain a challenge to the non-Humean, whatever we end up deciding about the Humean accounts currently on offer.

\section{Defending premise 2}

According to the non-Humean, the Oracle's testimony shows that the laws are very different than we originally thought. So if scientific practice tracked non-Humean laws, then we would expect that the Oracle's testimony to have dramatic effects on scientific

\footnotetext{
${ }^{25}$ Not even argument (III) - about the post-Oracle success of scientific projects-made any claims about what Humean laws can or cannot do. It merely relied on the claim that scientists would be able to continue successfully pursuing their projects, given that the scenarios in question are exact Döppelgangers of the actual world.
} 
practice. But, I have argued, it would not. So, at least prima facie, Premise 1 raises a problem for the non-Humean.

But there are various ways the non-Humean might explain this result (i.e., explain how Premise 1 could be true even though scientific practice does, in fact, track nonHumean laws). For example, one might agree that scientific practice would not alter, but maintain that scientists would be engaging in fiction or pretense. Or one might claim that this return would involve a reconceptualization of the aims of scientific practice. Or one might maintain that this return would be accompanied with a corresponding rejection of the Oracle's testimony. In this section, I discuss responses of this kind.

\subsection{Fictionalism}

I will use the label 'fictionalism' to encompass views on which law-related aspects of scientific practice involve fiction, pretense, or non-literal speech. If scientists are merely pretending that laws exist, then it is no surprise that scientists continue talking about laws even after the Oracle.

One problem with this proposal is that there is no independent evidence for fictionalism about laws. For example, if someone says "He has a heart of stone" and a child asks "What type of stone?", the original speaker will clarify that she was not speaking literally. ${ }^{26}$ The same goes for all other clear cases of non-literal or fictional discourse. But in contrast, scientists have no inclination to retract their law judgments in response to queries like "Is Schrödinger's Equation really a law?"

The fictionalist might reply that, while scientists do not normally retract their judgments about objects, they might indeed retract them after hearing the Oracle. I agree that this might happen in certain contexts: those contexts where scientists are specifically prompted to think about the Oracle. But set these cases aside. Instead, imagine an "ordinary" scientific context where someone might ask if Schrödinger's Equation is really a law; imagine, for example, a student who is wondering whether Schrödinger's

\footnotetext{
${ }^{26}$ See Burgess \& Rosen (1997, 532-534).
} 
Equation is merely a useful heuristic. In this kind of "ordinary" scientific context - in other words, a context where scientists are going about their everyday work of investigating and teaching physics - the professors would not retract their judgments (if only because the debate about Humeanism would not even cross their minds; see the discussion of scientists' typical indifference to the debate over Humeanism in 3.4). So, at minimum, fictionalism is not sufficiently general. More importantly: in 3.1, I explained why "ordinary scientific contexts" are the ones most relevant to my argument.

A second worry is that fictionalism fails to use the term 'non-literal' with its ordinary meaning. In ordinary use, this expression serves to demarcate judgments of a certain, clear type: 'He has a heart of stone', 'She was kept in the dark', etc. So the worry is that, by viewing all of the judgments in a certain area of discourse as non-literal, the fictionalist is simply failing to use the distinction between literal and non-literal discourse in the ordinary way. ${ }^{27}$

While fictionalism deserves consideration, I think these shortcomings suggest that it is not an adequate explanation of the Oracle cases.

\subsection{Reconceptualization}

The second non-Humean explanation of Premise 1 is that the Oracle's testimony would trigger a reconceptualization of the scientific project. On this proposal, the nonHumean grants that scientific practice would "appear the same" after the Oracle's testimony (in the sense that, e.g., scientists would evaluate counterfactuals as they did before, etc.). But this, the non-Humean claims, is only because the conceptual foundations of scientific inquriy would change after the Oracle. Originally, scientific practice aimed at non-Humean laws. But post-Oracle scientific practice would aim at Humean laws instead. In other words, the term 'law' would undergo a semantic shift.

The problem with this proposal is that there is no independent evidence for conceptual change. The three major factors thought relevant to reference determination are

\footnotetext{
${ }^{27}$ Similar remarks apply to proposals that view law discourse as involving pretense or fiction.
} 
environment, usage, and speaker's intentions. A shift in environment explains why, e.g., the term 'water' shifts reference after spending sufficient time on Twin-Earth. But this does not apply to the section 3 cases, where we assume that scientists remain in the same environment.

As for usage: I have argued that the Oracle's testimony would not affect those aspects of scientific practice related to the laws of nature. This discussion supports the claim that the term 'law' would have the same inferential role within scientific discourse that it did before the Oracle's testimony. ${ }^{28}$

Might a change in scientists' semantic intentions indicate conceptual change? One problem with this proposal is that it is insufficiently general. While we can imagine some scientists changing their semantic intentions after returning to scientific work, we can imagine other scientists for whom the thought simply never crosses their mind. Indeed: scientist's typical indifference to questions about what might or might not be "behind the scenes" governing the Humean mosaic (see 3.4) makes this very easy to imagine. So any change in speakers' intentions would not be sufficiently general.

But more fundamentally, scientists' indifference to what might be beyond the Humean base is itself a reason why the current suggestion fails. It is because scientists are indifferent in this way that all linguistic dispositions (and related semantic intentions) that actually matter to the use of the term 'law' in scientific practice would remain the same after the Oracle's testimony. So any alleged change in semantic intentions would be semantically idle.

To this point, I have argued against there being any semantic shift in the term 'law'. But there is a second way to understand the reconceptualization proposal. Consider how modern physics has changed our understanding of solidity. The discovery that solid objects do not contain a plenum probably did not (strictly speaking) shift the meaning

\footnotetext{
${ }^{28}$ But how could the inferential role remain the same given that Humeans and anti-Humeans disagree on nested counterfactuals, nomic possibility, and explanation? As discussed in 3.6, recent Humean accounts are designed to align with what scientists say about these phenomena. I assume, as a working hypothesis, that the Humean adopts such an account. (See the arguments of 3.6 for further discussion.)
} 
of the term 'solid' (consider, e.g., that we do not view people's solidity judgments to be (almost) uniformly false prior to the advent of modern physics). But even so, we might naturally regard the change in our understanding of solidity as itself a form of reconceptualization.

Returning to the original case, might a change in scientists' understanding of the laws - a change resulting from the Oracle's testimony-itself explain why post-Oracle scientific practice does not alter ${ }^{29}$ In fact, I think this proposal encounters problems similar to those discussed above. First, the proposal is insufficiently general. While we can imagine some scientists changing their theoretical understanding of the metaphysics of laws due to Oracle's testimony, we can imagine other scientists for whom there is no such change. Again, this is especially easy to imagine given that scientists are typically indifferent to the debate over Humeanism (see 3.4). Indeed, we can be sure that many scientists (like most non-philosophers) have never considered the question before, and so have no theoretical views on the metaphysics of laws to begin with. So the current proposal is insufficiently general.

But just as before, scientists' typical indifference to the debate over Humeanism is itself the more fundamental reason why the current suggestion fails. To see what I have in mind, it is instructive to draw out the analogy with the solidity case. Notice that, even after physics changed our theoretical understanding of solidity, our use of the term 'solid' in everyday contexts did not change: we describe ice cubes, bricks, and chairs as solid just as we did before. To explain this continuity, one might appeal to reconceptualization: the objects we previously judged to be solid on the basis of the plenum conception we now judge to be solid on the basis of a revised microphysical conception.

But, while this is indeed a paradigmatic case of reconceptualization, it is implausible to suppose that this reconceptualization explains the continuity of our solidity judg-

\footnotetext{
${ }^{29}$ I thank an anonymous referee for this suggestion.
} 
ments. This explanation is implausible because it entails that our everyday solidity judgments are much more "theory-driven" than they actually are. We do not judge that chairs are solid because we judge them to have a certain microphysical structure. Nor did we (prior to learning physics) judge that chairs are solid because we judged them to contain a plenum. On the contrary: both before and after learning physics, we judge the chair to be solid simply because it looks solid, feels solid, and acts solid. Indeed, in typical everyday contexts, we are completely indifferent to what exactly the chair is like on the microscopic level: such thoughts almost never cross our minds. The point is that, even though solidity has undergone reconceptualization, this reconceptualization does not explain why we make the solidity judgments we do. This is because our theoretical conception of solidity is not "operating" in typical everday contexts: it has no effect on how we make judgments about solidity. ${ }^{30}$

One might disagree with some detail or other of how I have discussed the solidity case. Regardless, this discussion at least helps illustrate the fundamental problem with the present reconceptualization suggestion. Just as we are indifferent (in typical everyday contexts) to the underlying microphysical nature of solidity, so too scientists are indifferent (in typical scientific contexts) to the underlying metaphysical nature of laws (see 3.4). But then, just as the change in our theoretical beliefs about solidity does not explain the continuity of our solidity judgments, so too any (potential) change in scientists' theoretical beliefs about the metaphysics of laws does not genuinely explain the continuity of scientific practice post-Oracle.

(This discussion of scientists' indifference (in everyday scientific work) to the debate over Humeanism raises a question: why can't the non-Humean appeal to scientists' indifference itself to explain the thought experiments? In fact, I think that this explanation is basically correct. But as I discuss below, this explanation actually supports Humeanism.)

\footnotetext{
${ }^{30}$ Could it be operating tacitly? No: even little children who do not yet have the idea of a "microscopic level" can apply the term solid, and they apply it just like we do.
} 


\subsection{Rejection of the Oracle's testimony}

According to a third response, the reason scientific practice does not change is because, ultimately, scientists would come to reject the Oracle's testimony. One might think: scientists cannot reasonably engage in their projects while simultaneously embracing the Oracle's proclamations.

While interesting, this proposal also faces shortcomings. First: I have assumed throughout that the Oracle provides (near-enough) conclusive evidence $E$ (see 3.1). For example, we can suppose that the Oracle has made millions of correct predictions about surprising matters in the past. Given the extraordinary strength of this evidence, it would be epistemically irrational for scientists to reject $E .{ }^{31}$ So on the current proposal, we would have to say that scientists are epistemically irrational.

In addition, this response is not fully general. While we can imagine some scientists who decide to reject the Oracle's testimony before returning to scientific work, we can imagine other scientists who simply forget or stop caring about $E$ upon their return. We can also imagine scientists who never found the Oracle's testimony troubling to begin with. Just as in 4.2, scientist's typical indifference to questions about what might or might not be "behind the scenes" governing the Humean mosaic (see 3.4) makes this very easy to imagine.

\subsection{Summary}

With Premise 1, the non-Humean faces a challenge. If scientists track non-Humean laws, we would expect scientific practice to change dramatically after the Oracle's testimony. But according to Premise 1, it would not. In this section, I have considered three ways the non-Humean might explain this result in a way that is consistent with

\footnotetext{
${ }^{31}$ The non-Humean might reply that, at least in Humean world (see 3.2), it would not be irrational for scientists to reject $E$ because it would be extraordinarily unlikely for observed empirical regularities to obtain without something over and above the mosaic governing it. But this latter claim is at least as controversial as the thesis of non-Humeanism itself. And it hardly seems rational to accept a controversial philosophical thesis over a source of testimony that has made millions of (correct) surprising predictions. And regardless, this response is not applicable to the fragile world (see 3.3).
} 
non-Humeanism. But none of these responses are convincing.

So, instead, we ought to take Premise 1 at face value. The reason why scientific practice would not change after the Oracle's testimony is because scientific practice does not track non-Humean laws:

Premise 2: If scientists would not alter those aspects of scientific practice relating to laws upon receiving $E$, then non-Humean laws do not fill the roles that laws have in scientific practice.

Together with premise 1 , premise 2 implies:

Conclusion: non-Humean laws do not fill the roles that laws have in scientific practice.

One central observation throughout the above discussion is that, in the course of their everyday work, scientists do not care about whatever might or might not be behind the scenes governing the Humean mosaic (see 3.4). This is why scientific practice would continue much as before even after receiving the Oracle's testimony. But if this is right, why think that scientific practice tracks non-Humean laws? It is only plausible that it would do so if scientists cared about facts about what is "over and above" the Humean base in the course of everyday scientific work. But they don't: in scientific contexts, scientists make judgments about laws in complete indifference to such facts.

\subsection{Final objections}

I'll now consider some final objections.

Objection 1: The argument is circular. It is only when we assume that scientists accept the claim $P \equiv$ 'Humean laws can perform various types of work in scientific practice' that we are able to predict that post-Oracle scientific practice would not change.

Response: To show that the argument is not circular, I will consider the three specific arguments from 3.4 for why scientific practice would remain unchanged. Argument (II) appealed only to facts about human psychology. As for (I), the argument from 
indifference: this argument is actually in tension with $P$. The point with (I) is that scientists, when doing their everyday work, are not thinking about Humean vs. nonHumean laws at all. (But wouldn't scientists have to at least tacitly accept $P$ for scientific practice to remain unchanged? No-scientists do not require theoretical beliefs about Humean laws to go about their everyday work anymore than a child requires theoretical beliefs about ethics in order to do the right thing.)

As for (III), it requires the claims that: (i) if scientists track non-Humean laws, the Oracle's testimony would adversely affect scientific projects and (ii) scientists' projects would not be adversely affected by the Oracle's testimony (because, after all, the scenarios are exact Döppelgangers of the actual world). Neither of these claims presupposes anything like $P$. (Again, scientists do not require any theoretical beliefs about the metaphysical nature of laws when deciding whether to continue scientific practice.)

Objection 2: Suppose we grant that scientific practice aligns with Humean laws. No matter. Even if we drop the term 'law' entirely, we can still ask: are there non-Humean necessary connections in nature? And this questionthe question of real metaphysical importance - has nothing to do with how scientists use laws. Indeed, we might introduce a new term 'law*' that is stipulated to refer to non-Humean necessary connections and then debate whether there are laws*.

Response: This response is structurally analogous to the "Ontologese gambit" familiar from the metaontology literature, where the ontologist introduces a "metaphysicallyprivileged" quantifier in order to resist deflationary pressures from ordinary language. While I think the laws* gambit deserves further attention, it is outside the scope of this paper to consider it further. I will only observe that the debate over HS may look different after this gambit. For example, traditional arguments for non-Humeanism (or Humeanism) may no longer seem persuasive. 


\section{Deflecting arguments against Humean laws}

The Oracle argument is an objection to non-Humean laws. But the argument may have a further role in the debate over HS. To conclude the paper, I will discuss how the argument may also help deflect certain common objections to Humean laws. (Note, however, that the main argument of this paper does not require the success of the Humean responses considered in this section; see 3.6 for discussion).

To motivate the objections, consider a case discussed by Roberts $(2008,357)$ : a world with Newtonian laws where nothing exists except for a single particle traveling at a constant velocity. Prima facie, it seems that Humeans must deny that the single particle world is nomically possible (given Newtonian laws); after all, the Humean mosaic in this world is too impoverished to ground Newtonian laws.

This denial raises two problems. First: scientists treat cases like this as genuinely nomically possible (consider, e.g., a physics problem set concerning systems involving a single particle or just a few particles). Second: there are worries about nested counterfactuals (e.g., "had there been nothing but a lone particle, then had there been more particles than one, the force between any two particles would have accorded with Newton's law of gravity" ${ }^{32}$ ). It seems that the Humean cannot account for how laws are held fixed when scientists evaluate such counterfactuals (see 2.1 for discussion).

In addition, the above case serves as part of an alleged counterexample to HS. It seems possible for the laws of nature to be Newtonian except that $f=m a$ is replaced by $f=m a^{2}$. Given these modified laws, it is again nomically possible for nothing to exist except for a single particle traveling at a constant velocity. So, when comparing this world with the previous one, we have two worlds with the same Humean base but with different laws.

To respond to these objections, Roberts $(2008,357-361)$ provides a contextualist semantics for law statements. According to Roberts, the truth of law statements depends

\footnotetext{
${ }^{32}$ See Lange $(2009,54)$ for this kind of example.
} 
on which scientific theory is contextually salient. For example, when asked to consider a single-particle world with Newtonian laws, one enters a context where Newton's theory is salient. In such a context, the statement ' $f=m a$ is a law' is true. But when asked to consider a single-particle world with modified Newtonian laws, the salient theory changes and the statement ' $f=m a^{2}$ is a law' is true. So on this account, there is a single possible world considered from two perspectives. By distinguishing these contexts, the Humean can respond to this alleged counterexample.

This contextualist treatment also allows the Humean to address the worries about nomic possibility and nested counterfactuals. In the "Newtonian" single particle world, one assesses nomic possibility and one evaluates counterfactuals from the perspective of the salient Newtonian theory. This allows for the Humean to align with scientists' treatment of these issues.

The success of these responses depends on the plausibility of a contextualist semantics for law statements. To motivate this view, Roberts (2008, 96-105) offers the following thought experiment. Let $M$ be some value of mass that is greater than the total mass of all the matter in the universe. Assume that both of the following regularities obtain:

$$
\begin{aligned}
& P: f=m a \\
& P^{*}: f=\Phi(m) a, \text { where } \Phi(m)= \begin{cases}m & \text { if } m<M \\
2 m-M & \text { otherwise }\end{cases}
\end{aligned}
$$

$P$ and $P^{*}$ are two possible laws that make conflicting predictions about the behavior of bodies with mass greater than $M$. Now suppose that human scientists endorse the sentence ' $P$ is a law' but alien scientists endorse the sentence ' $P *$ is a law' (here, we can suppose that $P^{*}$ seems more natural to the aliens than it does to us). Roberts' intuition is that, in this case, both communities would be speaking correctly. He accounts for this intuition by offering his contextualist semantics. 
In response, the non-Humean may insist that there is a fact of the matter about who is correct about the laws. But the Oracle cases provide support for Roberts' view that ' $P$ is a law' is true as spoken by humans while ' $P *$ is a law' is true as spoken by the aliens.

After talking to the aliens, we can imagine human scientists worrying: "What basis do we have for thinking that $P$ is a law that the aliens do not equally have for thinking that $P^{*}$ is a law?" But for the same reasons that scientists would not let the Oracle's testimony impede their projects, so too scientists would not let their conversations with the aliens impede their projects. Insofar as scientists would still be able to successfully pursue their projects, they would continue to do so in the optimal way (and would not let the fact that the aliens make different judgments about the laws adversely affect their projects). If the aliens are relevantly similar to us, then analogous remarks will apply to them as well.

So we have two communities that agree on all relevant evidence, and neither is moved to change their practice even after dialogue with the other. The best explanation for this situation is that the term 'law' is context-sensitive in the way Roberts describes. ${ }^{33}$ As mentioned above, this provides the Humean with an attractive response to worries about nomic possibility, nested counterfactuals, and alleged counterexamples to HS.

\section{Conclusion}

In this paper, I have presented a new argument for Humean Supervenience. I considered (epistemically) possible situations in which scientists receive conclusive evidence that we live in a Humean Döppelganger. In other words, they receive evidence thataccording to the non-Humean - falsifies our law judgments, but which-according to the Humean - does not falsify our law judgments. I argue that, in these possible scenarios, all law-related aspects of scientific practice relating would remain unchanged. In other

\footnotetext{
${ }^{33}$ Alternatively, we might say that humans and aliens employ slightly different law concepts.
} 
words, scientists would treat the regularities "preferred" by the Humean as the laws. On this basis, I concluded that non-Humean laws fail to align with scientific practice. In addition, I discussed how this argument can defuse certain prominent objections to Humean laws.

\section{References}

[1] David Armstrong (1983). What is a Law of Nature? CUP.

[2] Helen Beebee (2000). The Non-Governing Conception of Laws of Nature. Philosophy and Phenomenological Research 61 (3):571-594.

[3] Harjit Bhogal (forthcoming). Nomothetic Explanation and Humeanism about Laws of Nature. In Bennett \& Zimmerman (eds.) Oxford Studies in Metaphysics.

[4] John Burgess \& Gideon Rosen (2005). Nominalism reconsidered. In Shapiro (ed.), The Oxford Handbook of Philosophy and Mathematics and Logic. OUP. 515-535.

[5] John Carroll (1994). Laws of Nature. CUP.

[6] David Chalmers (2012). Constructing the World. OUP.

[7] Chris Dorst (2019). Humean laws, explanatory circularity, and the aim of scientific explanation. Philosophical Studies 176 (10):2657-2679.

[8] - (forthcoming). Why do the Laws Support Counterfactuals? Philosophical Studies. doi. = 10.1007/s10670-019-00207-1.

[9] Fred Dretske (1977). Laws of Nature. Philosophy of Science 44 (2):248-268.

[10] John Earman \& John Roberts (2005). Contact with the Nomic: A Challenge for Deniers of Humean Supervenience About Laws of Nature Part II: The Epistemological Argument for Humean Supervenience. Philosophy and Phenomenological Research 71 (2):253-286.

[11] Kai Epstude and Neal J. Roese. (2008). The Functional Theory of Counterfactual Thinking. Pers Soc Psychol Rev. 12(2): 168-192.

[12] Michael Fowler (2002). Deriving Kepler's Laws from the Inverse-Square Law. http://galileo.phys.virginia.edu/classes/152.mf1i.spring02/KeplersLaws.htm. Accessed $02 / 15 / 2007$.

[13] Gilovich, T., Wang, R. F., Regan, D., \& Nishina, S. (2003). Regrets of action and inaction across cultures. Journal of Cross-Cultural Psychology, 34(1), 61-71.

[14] Michael Townsen Hicks. (2020) Breaking the explanatory circle. Philosophical Studies. https://doi.org/10.1007/s11098-020-01444-9

[15] .- (ms). What Humean Laws (Can't) Explain. https://static1.squarespace.com/static/52f14500e4b 06d419dd0886f/t/58dd12846a4963e5f5c756a2/1490883211192/What+Humean+Laws+\%28Can\% 27t\%29+Explain.pdf Accessed 11/13/2019.

[16] Michael Townsen Hicks \& Peter van Elswyk (2015). Humean laws and circular explanation. Philosophical Studies $172(2): 433-443$.

[17] Marc Lange (2000). Natural Laws in Scientific Practice. OUP.

[18] - (2009). Laws and Lawmakers Science, Metaphysics, and the Laws of Nature. Oxford University Press.

[19] — (2013). Grounding, scientific explanation, and Humean laws. Philosophical Studies 164 (1):255261. 
[20] Christian Loew \& Siegfried Jaag (forthcoming). Humean Laws and (Nested) Counterfactuals. The Philosophical Quarterly.

[21] Barry Loewer (1996). Humean Supervenience. Philosophical Topics 24 (1):101-127.

[22] - (2012). Two accounts of laws and time. Philosophical Studies 160 (1):115-137.

[23] Tim Maudlin (2007). The Metaphysics Within Physics. OUP.

[24] John Roberts (2008). The Law-Governed Universe. OUP.

[25] - (2015). Laws of Nature. In Humphreys (ed.), Oxford Handbook for the Philosophy of Science. OUP.

[26] Robert Stalnaker (1996). Knowledge, Belief and Counterfactual Reasoning in Games. Economics and Philosophy $12(2): 133$

[27] Amy Summerville \& Neal J. Roese. Dare to compare: Fact-based versus simulation-based comparison in daily life. Journal of Experimental Social Psychology 44.3 (2008): 664-671.

[28] Michael Tooley (1977). The Nature of Laws. Canadian Journal of Philosophy 7, 667-698.

[29] - (1987). Causation. Clarendon Press. 